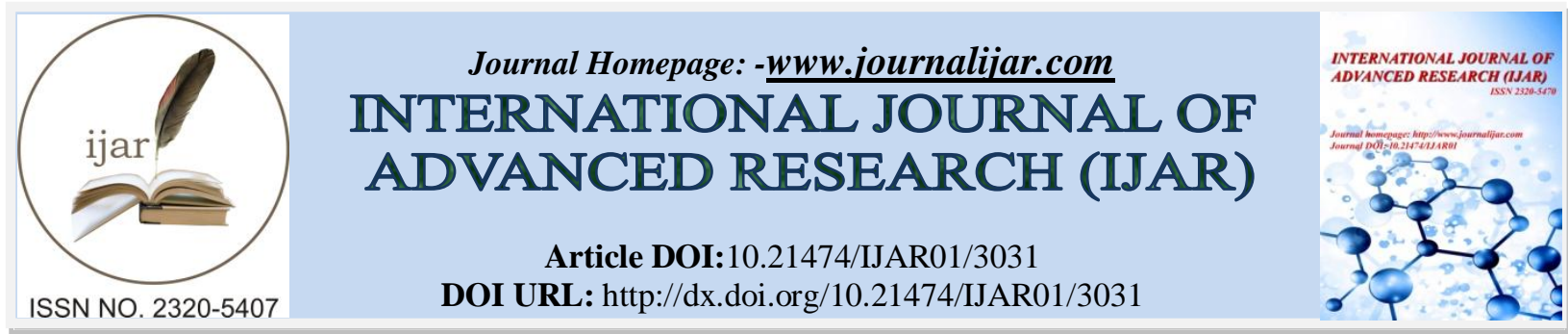

RESEARCH ARTICLE

\title{
DETERMINANT FACTORS THAT INFLUENCE SUPPLIER SELECTION FOR ONLINE BUSINESS SELLERS IN MALAYSIA.
}

Juwairiah Haris ${ }^{1}$ and Suzari Abdul Rahim ${ }^{2}$.

1. Researcher, Graduate School of Business (GSB), UniversitiSains Malaysia (USM), Penang Malaysia.

2. Senior Lecturer, Graduate School of Business (GSB), UniversitiSains Malaysia (USM), Penang Malaysia.

\section{Manuscript Info}

Manuscript History

Received: 30 November 2016

Final Accepted: 28 December 2016

Published: January 2017

Key words:-

Supplier selection, online business, online businessseller.

\section{Abstract}

In the current economic climate, online businesses are developing fast, with increasing responses from customers further encouraging online business. The use of IT enables wider opportunities for business expansionas well as presenting fresh challenges for businesses, whichhas led to many people deciding to venture into online business. When it comes to business success, the supplier plays an important role, and in choosing the right supplier, the overall performance of business operation can be immensely improved. Therefore, this paper aims to determine the factors that influence supplier selection for online sellers in Malaysia. In previous studies, the main focus proved to be research on supplier selection and the impacts of this on customer organisation and sales figures in physical stores, whereas this study will attempt to focus on online sellers; making the purpose of this study to identify and determine the factors that affect online business sellers in Malaysia in the selection of suppliers. Furthermore, this study attempts to use a combination of TPB and supplier selection criteria models to examine these factors. The increase of market globalisation and competition enabled by Internet-based technologies has contributed to significant changes in the order of stages in supplier selection factors, as well as introducing new criteria to the supplier selection process. As described above, gaps exist in previous research in this area, and there is an overall lack of research on this topic in Asian counties. Due to the lack of existing studies, this study contributes research by investigating the effects of quantity, quality, relationship, reliability, flexibility, delivery and cost on intention and their impacts on the behaviour of online sellers in Malaysia.It is hoped that this research will assist online sellers in selecting the correct supplier for their business, whilst reducing the overall costand enhancing business competency and clientservices. 


\section{Introduction:-}

Nowadays, the advance of Information Technology (IT) supports a large volume of user-generated content. IT provides more opportunities and challenges for business transformation. Many entrepreneurs have changed or expanded their business from a physical store to electronic business, which has also been accepted by users at the present time.

As proven by the exponential growth of existing online businesses, most consumers prefer to shop online. There are many e-commerce web stores that offer online purchase; such as ZALORA, Lazada, Groupon, 11street and Amazon. Some of the online sellers also sell through Facebook, Twitter and Instagram, which demonstrates that it is not only large organisations that can run business via online, but smaller companies such as enterprises, can also set up online stores and offer online purchase to their customers.

Supplier plays an important role in the success of enterprises. Choosing the right supplier determines the overall performance of business operation. When the chosen supplier provides the best quality of products with multiple options provided and at the best price, the sellers receive a lot of benefits, showing these enterprises have more chances to offer their customers the best selling. Therefore, it is important to understand and determine the factors that influence supplier selection because it could result in a significant impact on customer impression. Thus, the researcher aims to identify and understand determinant factors that influence supplier selection for online business sellers in Malaysia.

\section{Significance of the Study:-}

In previous research, there are a lot of literatures about quantity, relationship, reliability, flexibility, quality, delivery, cost, intention and behaviour in various areas (Camen et al., 2012; Teng\& Jaramillo, 2010). Even though there are a lot of literatures in these variables, there are very limited scholarswho focused on determinant factors that influence supplier selection for online business sellers in Malaysia. In Malaysia, there are many online sellers involved in this area. However not all business sellers could survive in the competitive marketsince they did not know how to choose the right supplier to supply the product. This situation affects their business performance and as a consequence, many sellers are no longer interested in continuingtheir online business.

The following are some of the practical benefits from this study which can improve knowledge and performance of online business sellers in Malaysia:

- The study on the factors that influence supplier selection for online business sellers in Malaysia provides the important know-how regarding the significance of the supplier selection, enabling them to gain greater profitability whilst achieving higher productivity in supply chain, higher level performance for their business and further enhancement its competitiveness in the marketplace.

- The results of the study can also be applied by online business sellers in Malaysia to determine their objectives and future direction.Therefore, better strategy planning can be achieved when making a decision, leading to better company reputation on a global scale.

- This study highlights the determinant factors that influence supplier selection for online business sellers in Malaysia. Thus, this provides a guideline to online business sellers in Malaysia in selecting the best suppliers and therefore encouraging them to invest in these initiatives using the right methodologies, without affecting business reputation.

- This study provides useful insights for online business in Malaysia regarding the roles that influence supplier selection. This is important to enable online business sellers identify the important factors that can help them improve their performance in business and lead to increased productivity.

In terms of research contribution, this study attempts to enrich the current published literature by providing empirical support on the determinant factors that make effective supplier selection for online business sellers in Malaysia. This study will also extend the theory and model and enhance the literature on determinant factors that influence supplier selection for online business sellers in Malaysia. Therefore, it is hoped that this research will be of benefit to the scholarly practitioner, researchers, and in particular online sellers in Malaysia, thus contributing to improving Malaysia's economic scale. 


\section{Objective of the Study:-}

Generally, long term cooperation relationships give positive impacts to online sellers. Therefore, selecting the right supplier is very important to achieve the objective and goals. Thus, the objectives of this study are:

- To investigate the factors that influence supplier selection for online business sellers in Malaysia.

- Examine factors that give an impact on online seller performance.

- Identify the relationship between intention and behaviour for supplier selection.

- Investigate intention and behaviour that influence supplier selection.

\section{Literature Review:-}

Problem Statement and Issues:-

According to Alstete (2002), many entrepreneurs faced obstacles when starting and running their businesses. Among those barriers, one that is crucial is supplier selection. It is necessary for each company and seller to have supplier evaluation processes,suggesting that selecting the supplier is a fundamental early step in running a business. Measuring supplier performance is important to ensure a well-functioning supply chain and company competitiveness. The goal is to improve performance, especially of the key suppliers. Understanding supplier performance may help sellers to prevent risk andimprove cooperation. Evaluation is necessary to know that the supplier is doing well in each area of action. Therefore, careful selection of supplier's evaluation criteria is important.

With the use of internet as a new platform in business, entrepreneurs will have more opportunities to structure and restructure their businesses, utilising all those possible mediums to market their goods and services as well as finding the best possible sources and suppliers which can offer them fruitful, favourable returns. Also, globalisation offers everyone the same chances to use the internet, making it an essential requirement for business sellers nowadays. Thus, most business sellers are now taking steps to use the internet as a platform for their business activities. Therefore, businesses are now able to run 24 hours, 7 days a week without the constraints of time and place. Although online businesses in Malaysia are increasing, there are several factors that may directly or indirectly influence their effectiveness; such as the products offered, reliability, suppliers, cost, etc.

Every business wants quality products. This is because product quality would ensure customers'satisfaction and thus will benefit the traders. Online businesses should always make sure the goods or services to be sold to the end user have high quality with a low cost. Thus, selecting a supplier is a tough decision. Online sellers are faced with myriads of possible risks if they chose the wrong supplier. The risks are usually related to their company profit and money.Therefore, online businesses should be careful in selecting suppliers, because wrong selection will affect their profitability.

Security is also a crucial factor in looking for suppliers. When trust exists it means that online sellers will feel secure and be assured of their relationship with the supplier. Security includes various aspects, for instance, product details and information, warranty, supplier identity confirmation as well as reviews of the products or services. There are many cases of identity theft using the information provided online by the individual who seeks to steal money from the personal account of someone who does internet banking. There are also many issues that need to be considered in addressing the issue of security for the future stability of the online world. Because personal and financial information can be intercepted and used for fraudulent purposes, an online investment involves a greater safety concern than conventional trade. Users need to feel safe when conducting financial transactions, and it is still one of the main obstacles to the growth of e-commerce (Lee and Turban, 2002).

In addition, who to buy from and how much to buy are some simple, basic questions yet critical during supplier selection processes. Suppliers who possess the criteria that can help reducing sellers' costs and have effective control of resources should be chosen first as they offer enormous potential to online sellers. Many researchers stated that the most important function in the purchasing department is selecting the sources of supply. Performance of the company will be affected if they make an unsuitable selection. Thus, online sellers should keep updated with the demand from a new supplier. They should carefully select those criteria that can fulfill supplier's demands as well as their demands during the decision making process. 
One thing to be emphasised, is that the quality of the production and services mainly depends on the performance of suppliers. This is why effective purchasing is very important, because it can bring competitive advantages to online business accomplishment. However, the big issue that is always highlighted by the entrepreneurs is suppliers cannot provide the highest quality of the products they supplied but they offer the lowest cost of the product in the market. In other words, quality and cost tend to be two conflicting factors.

Practically speaking, product quality and cost are difficult things to determine (Baxter et al., 1989;Manoochehri, 1984). Sellers should refer to the overall quality performance which helps supply chain managers to select the right sources of supplies with the consideration of time, delivery and price. In this study, the researcher will demonstrate that quality and costs play an important role and they are interrelated.

Our daily life is greatly simplified with advanced technology, including buying and selling online. Online business is not something new but a transition from conventional methods in store to a cyberspace platform. Nowadays, technology advances in social media such as Facebook, Instagram and Twitter can be seen as an opportunity for sellers to generate income using different mediums. It lets many business sellers out there try their luck with online business. However, do they realise that they need to register as a merchant business with Company Commission of Malaysia (SSM)? The main concern of registering with SSM is the safety of consumers when buying and selling online. Besides the need to register with the SSM under the Registration of Businesses Act 1956, the business must also comply with Regulation Consumer (Electronic Transactions, 2012) enforced by Ministry of Domestic Trade, Co-operatives and Consumerism (KPDNKK).

Malaysia is moving from Sales and Services Tax (SST) to Goods and Services Tax (GST) and it was first introduced in Malaysia on 1st April 2015. In this respect, Malaysia Internet Entrepreneur Association (PUIM) expected that small online businesses would be affected by the implementation of the GST. According to the President PUIM MohdAzrulMohdNor, more than $85 \%$ of online sellers in the database PUIM consist of those who conduct business on a small scale.This means that they do business whether as an employee or assisted individuals only. Many businesses are still new in this field and the implementation of GST gives them surprising news because there are new members registered with SSM. Businesses that have a transaction worth more than RM500,000 per year are expected to receive the most significant effect. If GST is implemented, then the online sellers have to increase the price of their goods, which is a disadvantage to both the consumers and sellers.

Apart from that, effective supplier relationship can be developed if the supplier selection is appropriately done in the early stages. Supplier selection is a very important aspect in a business. Whether it is a small or large business; or if it is an offline or online business, it is the matter of choosing the right supplier that needs to be prioritised. The right selection of suppliers will also show the way and objective of the company. Previous empirical research also showed that the knowledge in selecting supplier is useful for managing various activities in supply chain. For example, the factors like quality, delivery and price have to be considered for supplier selection and the scientific way of selecting the supplier will enhance the function of overall supply chain.

Increased competition and globalisation of markets facilitated by Internet-based technologies have contributed to dramatic changes in the ranking of supplier selection factors as well as introducing new criteria to the supplier selection process. Due to the lack of research in Asian countries and existing gaps in previous studies as described above, this study investigates the effects of quantity, relationship, reliability, flexibility, quality, delivery and cost on intention and their impacts on behaviour of online sellers in Malaysia.

\section{Research Gap:-}

Previous studies indicated that most of the focus study in supplier selection was on customer organisation and sales in physical stores (Park \& Chang, 2010; Ordoobadi, 2009; Teng et al., 2005). There is only few research of supplier selection targeted in the Malaysia context (Muhammad et al., 2006) and there are no studies which examine the satisfaction of the online seller when choosing the supplier. This study aims to explore and view the scope of supplier selection that affects business online sellers in Malaysia. This will be done by examining thoroughly all the factors listed in the previous section. 


\section{Theory Used:-}

The Theory of Planned Behaviour:-

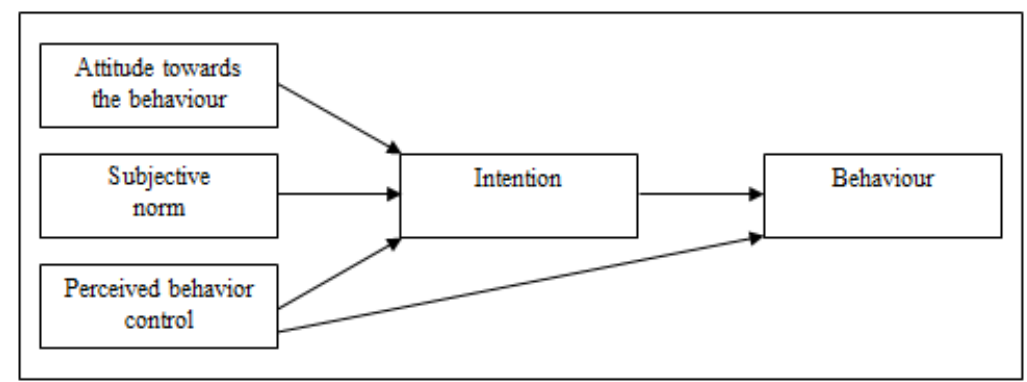

Figure 1:- The theory of Planned Behaviour

Theory of Planned Behaviour (TPB) is a theory to explain the intent of the individual to do a particular behaviour (Azjen 1991). TPB is a theory that has been recognised in the field of psychology, which aims to predict and explain human behaviour. TPB is a continuation of the theory of Reasoned Action (TRA).

Any behaviour must be accompanied by intention. Intention can be seen as a factor that motivates and influences the behaviour of an individual. According to these scholars, attitude, subjective norm and perceived behavioural control reflect intention and influence individual behaviour. Intention will affect behaviour when the individual has a personal positive attitude towards particular behaviours. Normally, the behaviour that is taken by an individual is because of the belief that the action taken was liked by others.

This study uses TPB to investigate the factors that influence the intention of online sellers that will influence their supplier selection. TPB has been used in many different studies in information systems (Mathieson, 1991). TRA and TPB have also been the basis for several studies of internet purchasing behaviour (Limayem et al., 2000;Jarvenpaa and Todd, 1997 b).

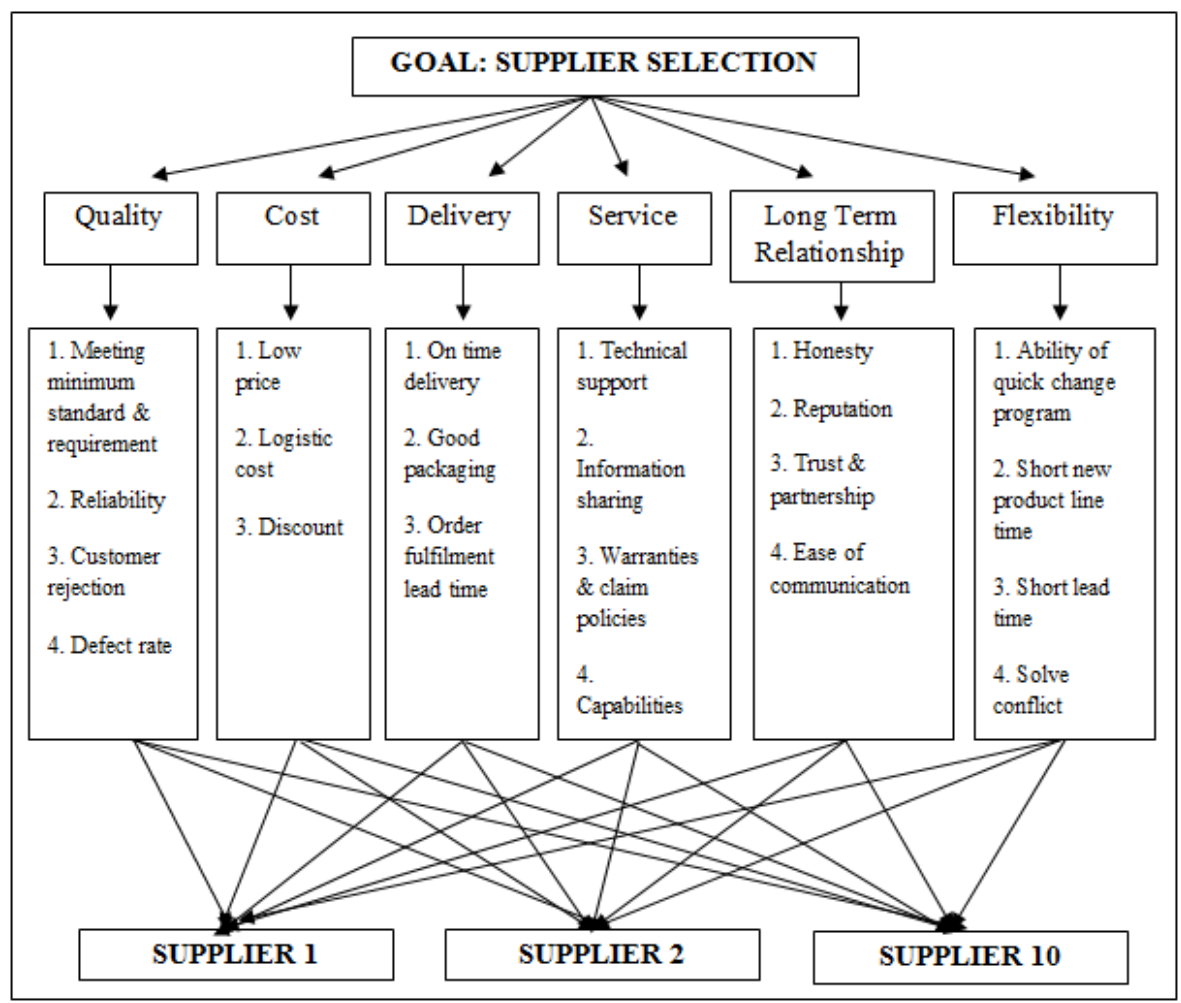


Source: Adoption from Yadav\&Sharma (2016)

Selection of suppliers has a big impact because it will affect the operation after the selection (Yadav\& Sharma, 2016). Supplier selection processes will usually be influenced by the criteria needed to solve the problem (Lui et al., 2005). Therefore, selecting the supplier is complicated because there are a lot of criteria to consider. Online sellers should be careful in choosing suppliers and examine the factors that can help them with later sales operations.

There are two aspects that are emphasised upon when choosing the supplier; the assessment of suppliers and procedures and methods when selecting the supplier. Online sellers need to understand that each supplier has a different background and organisation (Yadav\& Sharma, 2016). They have a different concept for the management of their operations. Therefore, it is a question of how to choose the appropriate one when the seller selects suppliers. Online sellers should evaluate several factors such as quality, cost, delivery, services, relationships, flexibility and others. Business success often depends on the construction of a network built with the supplier and thus making informed decisions in choosing the supplier is very important (Yadav\& Sharma, 2016; Matook et al., 2009).

In this study, researchers have combined TPB and supplier selection criteria in building a theoretical model of the new framework, with the aim of determining factors that influence supplier selection for online business sellers in Malaysia. It is hoped that the results of the study will help sellers in Malaysia to carefully consider the factors affecting their business and make the right decision in choosing the supplier.

\section{Theoretical Framework:-}

Figure 2 below shows a model that focuses on aspects of quantity, relationship, reliability, flexibility, quality, delivery, cost, intention and behaviour.

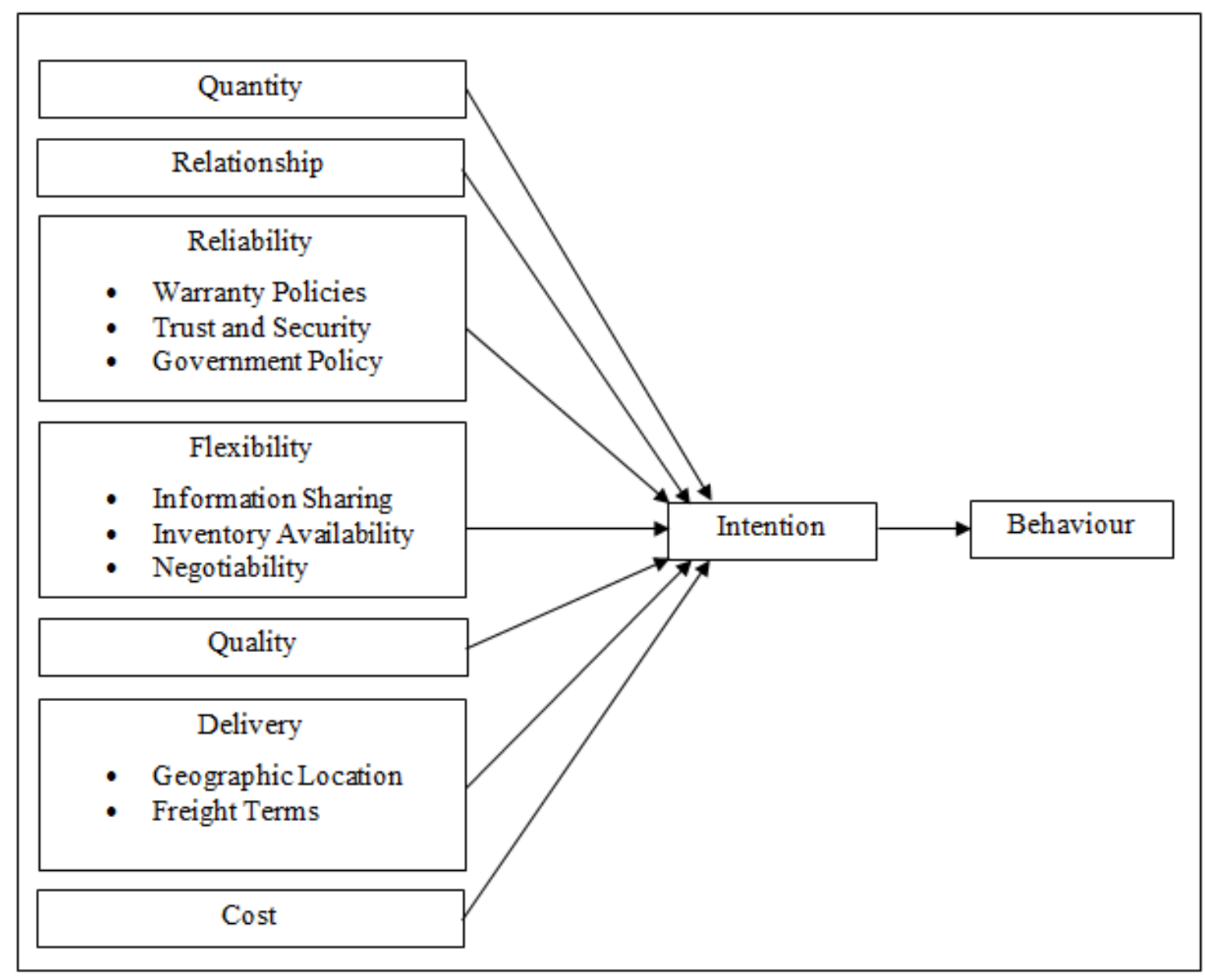

Figure 2:- Conceptual Research Framework 
The purpose of this study is to determine factors that influence supplier selection for online business sellers in Malaysia. The hypotheses concern the following nine variables; quantity, relationship, reliability, flexibility, quality, delivery, cost, intention and behaviour.

\section{Quantity:-}

Quantity is an important element to consider when choosing a supplier. Providing a minimum order quantity (MOQ) is among the characteristics of suppliers preferred by online sellers. However, quantity discount changes following the orders placed. Quantity discount contract is an important element and is influenced by several factors; inventory is one of these factors. The use of quantity discounts is a way to streamline the buyer and seller and it is commonplace in the supply chain. Normally, the more quantity the online seller buys, the cheaper price per unit of goods to be purchased. However, it is difficult for online sellers when buying in large quantities because they need to keep the goods as ready stock.

In addition, online sellers also take the risk because the purchased goods will not necessarily get demand from their customers, thus there is no guarantee that all the stock can be sold in a certain period of time. It is important for a company to reduce their inventory costs and find a balance between the number of orders per year and annual holding costs. Minimising the quantity of orders can indirectly provide an opportunity to explore new opportunities in market. Therefore, in this study, the researcher will examine the relationship between quantity and intention. Thus, the following hypothesis is proposed:

Hypothesis 1:- Quantity has a positive impact on intention.

\section{Relationship:-}

Establishing good rapport is often the element that will contribute to a positive relationship between two parties. In business, online sellers can build relationships with suppliers through various transactions. Normally, this relationship occurs if the online seller gets satisfied with what they want. However, online seller acceptance is different according to their motivation and vision. Relationship on the length of time not only depends on the intent provider only, but should be in line with the online seller's intention to continue to conduct transactions with suppliers (Deb, 2014). Thus, among the issues in developing online seller-supplier relationship is not just the demand from supplier, but also lies with the online seller. Some online sellerswill not feel the need for a relationship and this usually causes this relationship not to apply.

Relationships between suppliers and retailers, especially online sellers has not been studied very much before. Therefore in this study, the researches wanted to know whether the relationship is very important in the selection of suppliers' online seller and thus this hypothesis is proposed:

Hypothesis 2:- Relationship has significant impact on intention.

\section{Reliability:-}

In this study, researchers wanted to investigate the aspect of reliability related to warranty policies, trust and security.

\section{Warranty Policy:-}

Warranty is also known as an important contract between producers and buyers. Warranty refers to a contract that requires manufacturers and vendors to fit problems or failures in the promised time frame. Warranty can be seen as a form of guarantee of manufacturing to customers for the reliability of its product to consumers. If the product fails to function properly, it is the responsibility of the manufacturer to provide services such as new product replacement, repair or refund payment. Warranty attracts the eyes of customers to purchase goods and services, as they know that they have the rights to complain, refund and replace what they have purchased.

Online sellers need to take a high risk if the goods are sold to the end user have damage and how they as a seller handle this problem. If there is any damage, online sellers need to answer and respond to it. But if the damage is born by the manufacturer, it is a good thing that can promote their business. Therefore, to determine whether the warranty had a positive impact on intention, the following hypothesis is proposed:

Hypothesis 3a:- Warranty policies have a positive impact on intention. 


\section{Trust and Security:-}

Trust in online transactions is one of the main elements of success in online selling businesses. The result of trust is very significant on influencing buyers' intention and behaviour.Lack of trust leads to lack of customer acceptance on online purchasing. The purpose of establishing trust is to develop a continuous interaction and acceptance which has a high probability of leading to long-term commitment of business relationship.

Normally, online sellers will use the internet as a medium to find suppliers. So, it is an important issue if the website or online store owned by the suppliers does not provide trustable sources or information, which is less likely to lead to a purchase action. Suppliers need to understand the basic things that can help in building confidence in the online seller. If the trust existsin the supplier, it will improve the online sellers' intention to have a relationship in business.

Apart from trust, security is another reason of selecting a supplier. If the online businesses develop trust in a supplier, it also means that they are assured on the security of the deal. In other words, they have been assured of the goods' safety and quality as well as supplier identity. Being assured of these whole aspects is important because there are cases of goods defects and identity theft which results in a big loss to the company. In the case of identity theft, this issue is quite common nowadays since there are people who can hack the internet banking sites to steal money and personal information. This issue is a big threat in online business and needs to be considered for the future stability of e-commerce (Lee and Turban, 2002).

Therefore, there must be trust and security in online trading companies and the security features should be taken into account so that they can encourage online sellers' behaviour in online payment transactions. In this study, the researcher will also examine this aspect of trust and security with intention toward behaviour. Thus, the following hypothesis is proposed:

Hypothesis 3b:- Trust and security has a positive impact on intention.

\section{Government Policy:-}

Government policies play an important role in promoting innovation and drive the country towards high technology. In this study, researchers wanted to see whether the government's policy is helping online sellers, or whether regulations became a burden. Internet is a new medium that is used by the warm user everywhere. It is a communication tool that can connect one person to another regardless of frontiers. With the advent of new media in Malaysia, the Malaysian government is faced with various challenges. These challenges can be used for development of the country or can pose a risk.

New medium known as Information and Communications Technology (ICT) can help in the economic development, but in reality it is difficult to be controlled and monitored. If viewed from the perspective of online businesses, the Malaysian government has implemented several new policies that should be followed. Among the things that have been emphasised upon by the government of Malaysia is the registration of companies in the Companies Commission of Malaysia (SSM). The SSM's vision is "to be a world class corporate and regulatory authority that meets business needs through effective registration, information, regulation and advice"

There is a question on the necessity to check the SSM, because many users now prefer shopping online. Therefore, registering a company with SSM can increase confidence and trust of internet users with business status, and thus indirectly boosts the credibility of the online company for the long term. If the online business faces any problem, especially with regards to the authorities, it is easy to solve because the company is already legally registered.

Canada started GST on January 1st, 1991; Singapore on 1st April, 1994; Australia also introduced GST in July 2000; while Malaysia started on April 1st, 2015. Looking at other countries and their implementation, Malaysia looks delayed in the implementation of the GST. Malaysia has changed from sales and services tax (SST) to the Goods and Services Tax (GST). GST is a tax on domestic consumption. It must be paid when the money is spent on goods or services, including the purchase of imports. Since GST is a tax on the transaction, it is subjected to every level of business processes and ultimately can be born by consumers. Therefore, the following hypothesis is proposed:

Hypothesis 3c:- Government policy has significant impact on intention. 


\section{Flexibility:-}

Flexibility is another factor that should be considered. This study would like to evaluate flexibility based on three factors; inventory availability, information sharing and negotiability.

\section{Inventory Availability:-}

Managing inventory is an important thing and it requires the power of suppliers and buyers forecasting sales (Ballou, 2000). Almost all of the literatures on inventory management state the important criteria in the inventory management are to minimise costs and maximise profit (Koumanakos, 2008). This is explained in the habit whereby suppliers aim to reduce a lot of the cost when it comes to production and at the same time seeking to maximise profits and meet customer demand.

Online sellers prefer to choose suppliers who can maintain a certain quantity of stock. Normally, suppliers will also ask the buyer to forecast the required amount in advance. This is to make sure that insufficient supply does not occur. In this study, factors of available inventory are measured in terms of quantity, whether the online sellers wants to buy in quantities less than expected or better than expected, and also whether the provider can give it to them. Therefore, the following hypothesis is proposed:

Hypothesis4a:- Inventory availability has a significant impact on intention.

\section{Information Sharing:-}

The second factor that needs to be regarded in flexibility is information sharing. Examples can be seen as the online seller updates necessary information related to inventory, production planning, order status, and many others. The supplier is also required to forecast quantities of stock to be purchased by the online seller to arrange the company's plans. In this situation, both sides need to have compatibility in information sharing (Teng and Jaramilli, 2005). Thus, the following hypothesis is proposed:

Hypothesis 4b:- Information sharing has a significant impact on intention.

\section{Negotiability:-}

Negotiability is the third factor for flexibility. Almost all companies use contract buyers and suppliers (Teng and Jaramilli, 2005). There are conditions required to be met by online sellers and suppliers, especially related to inventory. Negotiabilitycan be associated with mutual trust, whichhas existed in the supply chain for a long time (Min, 1994). Therefore, this study tries to assess whether the online seller is able to comply with the purchase agreement in accordance to the agreed quantity, and also whether this negotiable factor exists within the provider. Thus the following hypothesis is proposed:

Hypothesis 4c:- Negotiability has positive significant impact on intention.

\section{Quality:-}

Quality is one of the things whichshould be prioritised in the selection of suppliers. The word quality is rather difficult to understand and interpret. Everyone has their own interpretation of the word quality. Normally, quality is defined as the characteristics contained in a product and whether those features can give satisfaction to customers. Efficient quality management can help in achieving the success of a business. Thus, it could provide a competitive advantage in a market.

Quality can be divided into several aspects including user-based, manufacturing-based, value-based, product-based and transcendent. From these viewpoints, online businesses need to make sure that an item to be retrieved from the supplier should have the features as discussed. In this study, the main and most important point to note is user-based. It is very important for online businesses to sell what customers want. High demand for a product usually will promise fruitful opportunity to succeed in internet business. Therefore, the following hypothesis is proposed:

Hypothesis 5:- Quality has a positive impact on intention

\section{Delivery:-}

Delivery is one factor that should be a concern when selection of a supplier is made. Delivery factors can be viewed in detail in two parts: geographical location and freight terms. 


\section{Geographical Location:-}

Geographical location is more representative of the customer and is a determinant factor when selecting suppliers (Teng and Jaramilo, 2005). Not all suppliers can deliver the goods when the online seller's location is not included in the courier service company. For example,PosLaju has 5 zone coverage areas. Not all of them send directly to the customer, there are areas that require a customer to get stuff on their own in Pos Mini or outlets nearby. It usually occurs if the customer is considerably deepened. Therefore, in this study, the researchers want to examine in detail the factor of geographic location in the selection of suppliers for online sellers and thus this hypothesis is proposed:

Hypothesis 6a:- Geographic location has a positive impact on intention

\section{Freight Terms:-}

Freight delivery term of each company is different. Usually, a company will follow the conditions set by the rules of a nation (Teng and Jaramillo, 2005). Besides rules, each courier company has different price and freight term. In Malaysia, the courier services such as GDex, PosLaju, Skynet, Ta-Q-Bin, and City-Link have their own freight term and offer different prices as they strategies to attract people. Here, bureaucracyoccurs since each company targeted as many customers as possible in order to fulfill their company's objective. Therefore, online businesses should consider which courier suits their needs and offers the best deal. Choosing the right courier can save cost and guarantees the safety of the goods delivered. Thus, the following hypothesis is proposed:

Hypothesis 6b:- Freight term has a positive impact on intention.

\section{Cost:-}

Low prices for goods and services can attract customers to buy it. In this case, it shows customers will definitely prefer to buy quality goods at a low price. Thus, indirect sales revenues will continue to increase and may lead to increased profits. While offering low price goods, online sellers need to find suppliers that provide low prices to them. Low cost delivered by the supplier does not necessarily give satisfaction to customers. Evaluation and selection of suppliers of traditional methods are more focused on price and ignore the direct costs and indirect costs that are related to the delivery, use, spare parts, and other qualities. When all costs are taken into account, it will provide a greater effect than the actual cost price of the goods. This is because lowest offer may not represent the overall cost, quality and delivery to suppliers. Therefore, the following hypothesis is proposed:

Hypothesis 7:- Cost has a positive impact on intention.

\section{Intentionand behavior:-}

Online business has been growing rapidly due to the increasing consumer demand. In the context of e-commerce, intention of shopping online is caused by the main consequence of pre-purchase satisfaction. Through intention, one can predict the behaviour of online sellers. Rationally speaking, the reaction can only occur if the intention was present and that intention is to grow or be obstructed depending on the outcome.

According to Muhmin (2010), the evaluation criteria for the user, information search and evaluation has been carried out in advance. Thus, it is clear before making any purchase, online sellers will do research in advance and if the study of something is good, then it will encourage the intention to purchase. Intention reflects the desire of the user. Intention is described as the desire to do the behaviour.

Behaviour control directly or indirectly all depends on the intention. Individuals usually have the resources and opportunities necessary to perform the behaviour (Azjen, 1991). Thus, online sellers need to find detailed information when selecting suppliers. The presence of intention can persuade the behaviour to accept or reject the supplier. Intention that is present will affect the behaviour whether to accept or reject a decision made during the selection occurs. Thus, the following hypothesis is proposed:

Hypothesis 8:- Intention has a positive impact on behaviour.

\section{Methodology:-}

This study will discuss in detail the research methods that have been applied. The researcher attempts to determine the relationship between variables based on data obtained from a sample of a population. The researcher uses 
quantitative methods to collect data from the respondents. Figure 3 below shows the overview of the quantitative research process.

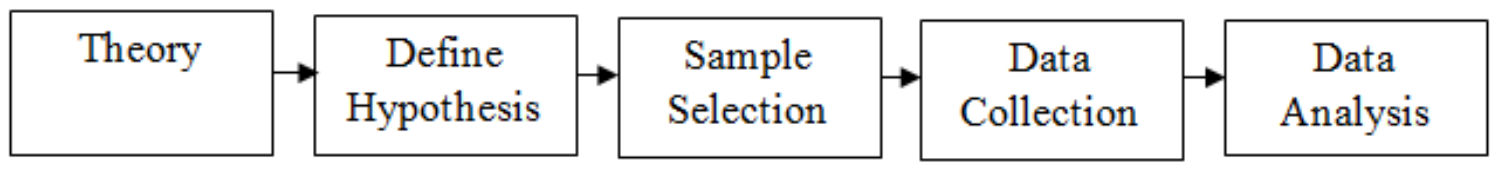

Figure 3:- Overview of quantitative research process

The population is the entire group of objects in the form of people, events or incidents or other objects to be studied (Sekaran, 2000). In this study, the target population comprises of individuals who currently run businesses online in Malaysia. This is in line with the objective of the study which is to determine the factors that influence supplier selection for online business sellers in Malaysia.

Sampling is a process of selecting a sufficient number of elements of the population in order to understand the nature or characteristics of the population. A proper sample thus allows for generalising the nature or characteristic elements of the population (Sekaran, 2000.) The target respondents of this study consist of online sellers who are currently running businesses via Online Social Networking (OSN) such as Facebook, Instagram, Twitter, You Tube, and others. In this study, convenience sampling was applied during data collection to achieve the objectives of this study.

The research was constructed using convenience sampling. As the name implies, convenience sampling is a specific type of non-probability sampling method that relies on data collection from population numbers who are conveniently available to participate in the study. Researchers used sample cases that are accessible, such as certain organisations or certain members on social networking sites as their participants (Rowley, 2014). The advantages of convenience sampling are the simplicity of producing the sampling and ease of research, data collection can be facilitated in a short duration of time and with cost effectiveness.

\section{Discussion and Conclusion:-}

The research conducted here inspects the elements that influence supplier selection for online business sellers in Malaysia, which will allow online sellers to learn about the factors that influence the selection of the supplier, as well as supporting them to make the most effective decision when attempting to choose the best type of supplier. Although online businesses may already have their own supplier selection ideas, this research hopefully couldoffer them some useful suggestion as an improvement in their strategy and direction in supplier selection. Following this research, it is expected that online sellers can be assisted in reducing the overall costs and improving their competency as well as client services, and other important aspects.

Author biography;-

JuwairiahHaris is a Doctor of Philosophy (PhD) student in UniversitiSains Malaysia (USM). She is currently studying $\mathrm{PhD}$ at the Graduate School of Business (GSB) with focusing on Supplier Selection area. She holds the qualifications of Post Graduate (Master in Business Administration, MBA) from USM (2015), Bachelor Degree of Management (Major Marketing) from USM (2010) and Higher National Diploma (HND) Business and Marketing from KolejProfesional MARA Seri Iskandar (2007).

Suzari Abdul Rahim is a Senior Lecturer in Graduate School of Business, UniversitiSains Malaysia. He received his Bachelor degree (Econ) from Staffordshire University UK and the Doctoral Degree (PhD) in Supply Chain Management from Brunel University of London, United Kingdom. Prior to his academic career, he has worked for various institutions in the Manufacturing and Telecommunications industry for a number of years fulfilling Supply Chain Management roles responsible for Procurement, Purchasing, Material Management, Supplier Relationship Management, Tender Management and Logistics. His current research interest is in the area of Halal logistics and supply chain management, investigating improvements and recommending logistics solutions for the Halal industry and community. 


\section{References:-}

1. Muhmin, A. G. (2010), "Repeat purchase intentions in online shopping: the role of satisfaction, attitude, and online retailers' performance", Journal of International Consumer Marketing, 23 (1), 5-20.

2. Ajzen, I. (1991), "The theory of planned behaviour", Organizational Behavior and Human Decision Processes, 50. $179-211$.

3. Alstete, J. W. (2002) "On becoming an entrepreneur: an evolving typology", International Journal of Entrepreneurial Behavior\& Research, 8(4), 222 - 234.

4. Ballou, R. H (2000) "Evaluating inventory management performance using a turnover curve", International Journal of Physical Distribution \& Logistics Management, 30(1), $72-85$.

5. Baxtor, L. F., Ferguson, N., Macbeth, D. K. and Neil, G. C. (1989), "Getting the message across? Supplier quality improvement programmes: some issues in practice." International Journal of Operations and Production Management, 9, 69-76.

6. Camen, C., Gottfridsson, P. and Rundh, B. (2012),"Contracts as cornerstones in relationship building", International Journal of Quality and Service Sciences, 4 (3), 208 - 223.

7. Deb, M. (2014) "A study on the factors governing retailer-customer long-term relationship", International Journal of Commerce and Management, 24(3), $257-272$.

8. Jarvenpaa, S.L. and Todd, P.A. (1997b), "Consumer reactions to electronic shopping on the World Wide Web", International Journal of Electronic Commerce, 1 (2), 59-88.

9. Koumanakos, D. P (2008) "The effect of inventory management on firm performance", International Journal of Productivity and Performance Management, 57(5), 355 - 369

10. Lee, M. K. O. and Turban, E. (2002), "A trust model for consumer internet shopping”, International Journal of Electronic Commerce, 6 (1), 75-91.

11. Limayem, M., Khalifa, M. and Frini, A. (2000), "What makes consumers buy from Internet? A longitudinal study of online shopping", IEEE Transactions on Systems, Man, and Cybernetics - Part A: Systems and Humans, 30 ( 4), 421-32.

12. Liu, J., Ding, F. Y. and Lall, Y. (2005), "Using Data Envelopment Analysis to Compare Suppliers For Supplier Selection And Performance Improvement," International Journal of Supply Chain Management, 3, 143-150.

13. Manoochehri G.H. (1984), "Suppliers and Just-In-Time Concepts", Journal of Purch. and Mgt., Winter, 16-21.

14. Mathieson, K. (1991), "Predicting user intentions: comparing the technology acceptance model with the theory of planned behavior", Information Systems Research, 2(3), 173-91.

15. Matook, S., Lasch, R. and Tamaschke, R. (2009), "Supplier development with benchmarking as part of a comprehensive supplier risk management framework", International Journal of Operations \& Production Management, 29(3), 241-267.

16. Min, H. (1994), "International supplier selection: a multi-attribute utility approach", International Journal of Physical Distribution \& Logistics Management, 24(5), 24-33.

17. Muhammad, J., Ndubisi, N. O. and Hing, L. H. (2006), "Supplier Selection Strategy and Manufacturing Flexibility: Impact of Quality and Technology Roadmaps" Asian Academy of Management Journal, 11(1), 1947.

18. Ordoobadi, S. M. (2009),"Development of a supplier selection model using fuzzy logic", Supply Chain Management: An International Journal, 14 (4), 314 - 327.

19. Park, J. S. and Chang, D. S. (2010),"A study on the difference of supply chain performance from thefitness between competitive priorities and supplier selection criteria", Asian Journal on Quality, 11 (2), 183 - 189.

20. Rowley, J. (2014). Designing and using research questionnaires. Management Research Review, 37(3), 308-330.

21. Sekaran, U. (2000). Research methods for business: A skill building approach(3rd ed.). Hoboken, MJ: John Wiley \& Sons, Inc.

22. Teng, S. J. and Jaramillo, H. (2005),"A model for evaluation and selection of suppliers in global textile and apparel supply chains", International Journal of Physical Distribution \& Logistics Management, 35 (7), 503 523.

23. Yadav, V. and Sharma, M. K. (2016) "Multi-criteria supplier selection model using the analytic hierarchy process approach", Journal of Modelling in Management, 11(1), 326 - 354. 